\title{
High Frequency Cotransduction of a Morganocinogenic Plasmid and Markers of R Plasmids
}

\author{
By J. N. COETZEE \\ Department of Microbiology, University of Pretoria, South Africa
}

(Received I3 June 1977)

\begin{abstract}
A converting phage for ampicillin resistance-phage $5006 \mathrm{Mp} a$-was used to transduce Proteus mirabilis strain PM5006 to ampicillin resistance. The infecting phage carried TnI as the source of its phenotype. The recipient had the conjugative plasmid P-lac as well as a non-self-transmissible plasmid as residents. The latter was a recombinant between a morganocinogenic plasmid MorI74 and R plasmid $\mathrm{R}_{772}$ which coded for kanamycin resistance. This recombinant plasmid had possibly undergone transductional shortening as a result of previous uptake by transducing phage 5006M. From these transductants, three transducing systems for transfer of morganocinogeny were obtained. The first consisted of the complete transduction of a plasmid expressing markers of MorI74 and ampicillin resistance at frequencies of about $\mathrm{I} \times 1 \mathrm{I}^{-5}$ per phage particle adsorbed. This frequency could have equalled that of the adsorption of transducing phage to recipient cells. The transduced plasmid was formed by translocation of TnI to the Mor I $74 \mathrm{R} 772$ complex with inactivation of the kanamycin resistance marker of the latter. The transducing phage was named phage 5006Mmora. The second - a high frequency transducing system for morganocinogeny, kanamycin and ampicillin resistances - was the result of markers of the Mor $74 \mathrm{R}_{772}$ complex inserting contiguously to TnI in the $5006 \mathrm{Mp} a-\mathrm{PM} 5006$ cryptic prophage sequence. The insertion converted the terminally redundant, circularly permuted phages into deficient phages lacking some (not always the same) genes and being unable to circularize (and hence lysogenize) due to lack of terminal repetition. The recombination of two defective genomes resulted in doublets which could reduce to the prophage state. This mutual aid explained the phage multiplicity dependence phenomenon encountered with this system. The phage was named phage 5006MHFTmorka. The third system of transduction resulted from deletion of non-essential genes from the oversized genomes just described. This restored terminal redundancy and consequently allowed individual genomes to circularize and thus transduce the three markers. This phage was named phage 5006 Mdpmorka. These phages also transduced their markers to $P$. mirabilis PMOXK, a strain to which only slight and variable adsorption of the phage could be demonstrated. Properties of the systems are described.
\end{abstract}

\section{INTRODUCTION}

Bacteriocin-positive transductants have been selected as a result of their lethal effect on indicator strains (Lovett, Duvall \& Keggings, 1976; Bramucci \& Lovett, I976; and see Threlfall \& Holland, I970). Provided the recipient is also sensitive to the bacteriocin produced by the transduced bacteriocinogenic material, the bacteriocin immunity phenomenon may also be used to select transductants (Tagg, Skjold \& Wannamaker, 1976; Fukumaki, Shimada \& Takagi, I 976). A third method is to select for the products of genes cotransduced with the bacteriocinogenic material in question (Fredericq \& Delhalle, 1972). Coetzee, Krizsanovich-Williams \& Williams (1977) reported the cotransduction of a non-selftransmissible morganocinogenic plasmid (Mor I74) derived from Proteus morganii 174 and 
the kanamycin resistance marker of $\mathrm{R}$ plasmid $\mathrm{R} 772$ by phage $5006 \mathrm{M}$ to $P$. mirabilis strain PM5006. The system was interesting in the sense that transductants were inducible, often lost the markers independently and, in the presence of P-lac (Falkow et al., 1964), could transfer transduced markers by conjugation. It probably meant that incoming recombinant transduced particles split into phage and, in some bacteria, separate MorI 74 and $\mathbf{R} 772$ components. A product of MorI 74 was possibly responsible for the cleavage. The phage portion would then integrate in tandem to the cryptic prophage of PM5006 to render transductants inducible. The R plasmid portion had probably undergone transductional shortening (Shipley \& Olsen, 1975) and this rendered it, and combined (or severed) MorI74, nontransferable by conjugation but still capable of independent replication. Induction of these transductants would yield some cotransducing phage particles. On transduction to a host which carried a resident conjugative plasmid like P-lac, these cotransduced particles, after severance of phage genes, would again be transmissible to other hosts. Transduction frequencies were low. In experiments reported here, attempts were made to increase the frequency. The strategy used involved attempts to add a transposon to the complex in the hope that possible accompanying deletions (Ahmed \& Johansen, 1975; Cabezón et al., I 975; Dempsey \& Willetts, 1976; Kopecko \& Cohen, 1975; Lee et al., 1974; Manly, Signer \& Radding, 1969; Reif \& Saedler, 1975, 1976; Starlinger \& Saedler, 1972, 1976; Kleckner et al., 1975) would shorten the material to an extent which would allow phage genes and the covalently linked Mor 74 complex to be contained in a single converting phage capsid (see Coetzee, 1977). The experiments were not successful, but three new systems for MorI 74 transduction were obtained. Two of these involved defective high frequency transducing phage for the markers concerned.

\section{METHODS}

Bacteria, plasmids and phages. These are listed in Table $\mathrm{I}$.

Media. Nutrient broth was Oxoid no. 2, code CM67. Nutrient agar was the same broth solidified with $\mathrm{I} \cdot \mathbf{2} \%$ (w/v) Difco agar. MacConkey agar was from Difco, and minimal medium was that of Grabow \& Smit (1967). When lactose utilization was the selected marker in transduction experiments, the minimal medium contained $0.3 \%(\mathrm{w} / \mathrm{v})$ lactose and $0.01 \%(\mathrm{w} / \mathrm{v})$ tetrazolium chloride (Grabow, 1972) instead of glucose. Buffered saline was $0.85 \%(\mathrm{w} / \mathrm{v}) \mathrm{NaCl}$ in $0.066 \mathrm{M}$-phosphate buffer $(\mathrm{pH} 7 \cdot \mathrm{I})$. Incubation temperature was $37^{\circ} \mathrm{C}$.

Drugs and antibiotics. Ampicillin, kanamycin and nalidixic acid were used at $50 \mu \mathrm{g} \mathrm{ml}^{-1}$. Streptomycin was used at $\mathrm{I} \mathrm{mg} \mathrm{ml}^{-1}$.

General phage techniques. These were described by Adams (1956) and Coetzee (1974b). With transduction experiments, the multiplicities of phage infection was usually not determined as the multiplicity of input (m.i.) of phages to bacteria was found to be a reasonable reflexion of the multiplicity of infection (m.o.i.) of host PM5006. This resulted in a negligible underestimation of transduction frequencies. Freeze-dried phage 34 antiserum (Coetzee \& Sacks, 1960) with a neutralization constant $(K)$ of $180 \mathrm{~min}^{-1}$ against phage $5006 \mathrm{M}$ was used.

Phage adsorption. This was as described by Coetzee (1976a).

Ultraviolet irradiation of phage and phage induction. These were done by the methods of Coetzee (1974b).

Purification and concentration of phage lysates. The caesium chloride method of Botstein (1968) was used. Lysates often contained many defective phage particles which did not register in ordinary plaque assay. To obtain a true estimate of the total particle titre of some lysates, the absorption of purified lysates was determined at $260 \mathrm{~nm}$ in a Beckman spectrophotometer. This was then compared with the absorption of a similar lysate of the wild-type phage $5006 \mathrm{M}$ of known plaque-forming titre. The plaque-forming titre of many lysates had to be multiplied by factors of 10, I4 or I6 to obtain total concentrations of phage particles.

Conjugal transfer of plasmids. The standard method was that described by Coetzee $e$ t al. (1973). When many potential donor cultures had to be screened, $0.3 \mathrm{ml}$ of mating mixtures and controls, constituted as above, were plated individually on very dry nutrient agar plates and incubated overnight. The growth was then replicated to selective media.

Detection of morganocinogeny. The replica-plating method of Williams (1977) was used.

Selection of segregants. Overnight broth cultures were plated on MacConkey agar to give about 50 colonies per plate after incubation. The plates were then replicated, by means of velveteen pads, to antibioticcontaining agar or to plates inoculated with the Mor 174 indicator strain. 


\section{Table I. Bacteria, plasmids and phages}

\section{Bacteria \\ Proteus mirabilis PM5006}

PM5006str-r

PMOXK

$\begin{aligned} & \text { Proteus morganii } \\ & \text { I63str-r }\end{aligned}$
Escherichia coli
J62-I
Plasmids
PM5006(P-lac)
PM0XK(P-lac)
PM5006(P-lac $\overline{\text { Mor } 174 \mathrm{~K}}) \dagger$

\section{Bacteriophages}

5006M.PM5006

$5006 \mathrm{Mp} a$

\section{Properties*}

Host for phages. Cryptically lysogenic for phage 5006M. Sensitive to A, K. Not susceptible to morganocin 174

Spontaneous mutant resistant to I $\mathrm{mg}$ streptomycin $\mathrm{ml}^{-1}$

Susceptible to many temperate and virulent Proteus phages. Adsorption of phage 5006M and its derivatives is slight $(<20 \%)$ and variable (for no apparent reason) and plaque formation could not be demonstrated. Sensitive to A, K. Not known to be lysogenic

Wild-type strain, resistant to morganocin 174 . Spontaneous mutant resistant to I $\mathrm{mg}$ streptomycin $\mathrm{ml}^{-1}$. Morganocin 174 indicator

Nalidixic acid-resistant mutant of $\mathrm{J62}$, an $\mathrm{F}^{-}$lac pro his trp mutant of $E$. coli $\mathrm{KI} 2$. Not susceptible to morganocin 174

P-lac plasmid confers the property of lactose fermentation and Su resistance on hosts. Introduced by conjugation

As above

Markers of morganocinogenic plasmid Mor 174 $\left(3 \times 10^{6}\right.$ dalton) and R plasmid R772 $\left(27 \times 10^{6}\right.$ dalton) were cotransduced with phage $5006 \mathrm{M}$ to PM5006 carrying P-lac as resident to produce a

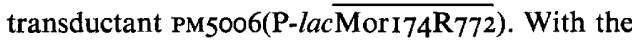
help of P-lac, the transduced recombinant was transferred by conjugation to J62-I. The latter transconjugant (again with aid of P-lac) could transfer the recombinant plasmid back to PM5006. P-lac did not always accompany the recombinant. Although this is a transconjugant, the superior line is retained to indicate the derivation of markers. Because the constitution of the recombinant plasmid is not known, $R_{772}$ has been replaced with its selected marker $\mathbf{K}$

Cryptic prophage of PM5006. Produced by lytic infection of PM5006. Generalized transducing for PM5006. Serologically identical to phages 34 and $5006 \mathrm{Mp} a$. Linear DNA approx. $23 \times 10^{6}$ dalton, circularly permuted, terminally redundant. Lysogens of PM5006 are converted to homologous phage non-adsorption

Carries TnI and is converting for $\mathbf{A}$

\section{Reference}

Coetzee \& Smit (1970),

Krizsanovich (1973),

Coetzee (1974a, 1975a),

Coetzee et al. (1977)

Coetzee (1976b)

Brandis \& Schwarzrock (1956), Vieu \& Ducrest (I96I), Vieu \& Capponi (1965), Coetzee (I975a, $b)$, Coetzee $(1976 a, b)$, Coetzee (unpublished)

Williams (1977)

Clowes \& Hayes (1968), Coetzee (1974a), Coetzee et al. (I977)

Falkow et al. (1964), Hedges (1975), Coetzee (unpublished)

Coetzee (unpublished)

Coetzee et al. (1977), Hedges (1975)

Coetzee \& Sacks (1960), Coetzee (196I),

Krizsanovich (1973),

Coetzee (1977),

Coetzee et al.

(unpublished)

Hedges \& Jacob (1974), Cohen (1976), Coetzee (1977)

* Symbols designate resistance to: A, ampicillin; K, kanamycin; $\mathrm{Su}$, sulphonamide.

$\dagger$ Throughout this paper, superior lines indicate that markers were transduced. 
Table 2. Properties of 21 2 transductants of transconjugant PM5006(P-lac $\overline{\mathrm{M} \text { or I } 74 \mathrm{~K}})$ by phage $5006 \mathrm{Mp} a$

Ultraviolet induction and transfer of markers to $E$. coli J62-I was done as outlined in Methods. Plate matings were first done and those transductants which failed to transfer markers were then tested by the standard fluid method. Non-selected markers in purified transductants were detected by replication to MacConkey agar containing antibiotics and to agar which had been seeded with the Mor 74 indicator strain.

\begin{tabular}{|c|c|c|c|c|}
\hline Transductant nos & $\begin{array}{l}\text { Plaque-forming } \\
\text { titre of lysate } \\
\text { on induction* }\end{array}$ & $\begin{array}{l}\text { Selected } \\
\text { marker }\end{array}$ & $\begin{array}{c}\text { Transfer } \\
\text { frequency } \\
\text { per donor cell }\end{array}$ & $\begin{array}{l}\text { Non-selected } \\
\text { markers }{ }^{\dagger}\end{array}$ \\
\hline$-157,159-208,210-2 \mathrm{I} 2$ & $5^{-8} \times 10^{9}$ & $\begin{array}{l}\mathrm{K} \\
\mathrm{A} \\
\mathrm{lac}^{+}\end{array}$ & $\begin{array}{r}8 \times 10^{-4} \\
<1 \times 10^{-8} \\
5 \times 10^{-2}\end{array}$ & $\begin{array}{l}\operatorname{lac}^{+}, \operatorname{MorI} 74(20 / 20) \\
- \\
\text { K, Mori74 }(8 / 12)\end{array}$ \\
\hline 8,209 & $5 \times 10^{7}+$ & $\begin{array}{l}\mathrm{K} \\
\mathrm{A} \\
\mathrm{lac}^{+}\end{array}$ & $\begin{aligned}< & \mathrm{I} \times 10^{-8} \\
< & \mathrm{I} \times 10^{-8} \\
& 8 \times 10^{-2}\end{aligned}$ & - \\
\hline
\end{tabular}

Standard and replica-plate transduction experiments. These were done according to the Millipore membrane filter technique (Coetzee, 1974b). In transductions which involved markers of antibiotic resistance, the membranes with impinged cells, after filtering, were incubated on nutrient agar for $2 \mathrm{~h}$ before transfer to selective media. Direct selection for markers of morganocinogeny was not attempted.

\section{RESULTS}

\section{Derivation of phage 5006Mmork $a$ and 5006Mmora}

Transduction of ampicillin resistance marker by phage $5006 \mathrm{Mpa}$ to transconjugant PM5006(P-lac MorI 74K $)$. Transduction of the marker (not shown) proceeded at a frequency greater than unity at the 2.5 multiplicity of infection used in attempts to secure entry of more than one phage genome per recipient (Coetzee, 1977). All transductants retained resident markers of the recipient.

Transfer of markers of transductants by conjugation. Two hundred and twelve transductants were screened for the ability to transmit markers to J62-I by conjugation. All but two of these transferred markers for morganocinogeny (Mor I 74), kanamycin resistance (K) and lactose fermentation $\left(l a c^{+}\right)$at frequencies of about $\mathrm{I} \times \mathrm{IO}^{-3}$ per donor (Table 2, lines I to 3). The transconjugants from this cross segregated the former two markers independently of $\mathrm{lac}^{+}$(not shown) and it was assumed that P-lac had merely acted as a conjugative plasmid (Coetzee et al., I977). The remaining two transductants (nos I 58 and 209) only transmitted the $\mathrm{lac}^{+}$marker at the high frequencies (Table 2, lines 4 to 6) previously encountered (Coetzee, 1974a).

Induction of transductants. Transductants which transferred the markers MorI $74, \mathrm{~K}$ and $l a c^{+}$to $\mathrm{J} 62$-I yielded lysates with plaque-forming titres of about $5 \times 10^{9} \mathrm{ml}^{-1}$ on PM5006 (Table 2 , line I). Only about $5 \%$ of plaques resembled the wild type. The remainder were hazy and about $\mathrm{I} \mathrm{mm}$ in diameter and resembled those produced by phage $5006 \mathrm{Mpa}$ (Coetzee, 1977). Replication of these titration plates to kanamycin or ampicillin agar showed that the growth in all the small plaques and in a variable proportion of the large plaques replicated to the ampicillin agar while none of the plaques replicated to kanamycin agar. These replica transductants (Coetzee, 1977) were all MorI 74-. The two transductants (nos I58 and 209) which only transferred the resident $l a c^{+}$marker, consistently produced lysates 


\section{Table 3. Transduction of markers by phage in induced lysates of PM5006(P-lac Mor I4KA) to strains of $P$. mirabilis}

Transductions were done as outlined in Methods. Adsorption was for $20 \mathrm{~min}$. Membranes were incubated on nutrient agar for $2 \mathrm{~h}$ before transfer to MacConkey agar containing ampicillin and/or kanamycin at $50 \mu \mathrm{g} \mathrm{ml}^{-1}$. Non-selected markers were detected by replication of purified transductant clones to other antibiotic-containing agar and to plates inoculated with the Mor 174 indicator strain. Conjugations were done as outlined in Methods.

\begin{tabular}{|c|c|c|c|c|c|c|c|c|}
\hline Lysate & Recipient & M.i.* & $\begin{array}{c}\text { Selected } \\
\text { marker }\end{array}$ & $\begin{array}{c}\text { Phage } \\
\text { 5006M } \\
\text { M.i.* }\end{array}$ & $\begin{array}{l}\text { Transduction } \\
\text { frequency } \dagger \\
\text { or no. of } \\
\text { transductants }\end{array}$ & $\begin{array}{c}\text { Non- } \\
\text { selected } \\
\text { markers in } \\
\text { trans- } \\
\text { ductants }\end{array}$ & $\begin{array}{l}\text { Lysogenic } \\
\text { trans- } \\
\text { ductants }\end{array}$ & $\begin{array}{c}\text { Conjugal } \\
\text { transfer } \\
\text { of } \\
\text { transduced } \\
\text { markers§ }\end{array}$ \\
\hline I & $\begin{array}{l}\text { PM5006(P-lac) } \\
\text { PM5006(P-lac) } \\
\text { PM5006(P-lac) }\end{array}$ & $\begin{array}{l}0.01 \\
0.01 \\
I \cdot I\end{array}$ & $\begin{array}{c}\mathrm{K} \\
\mathrm{A} \\
\mathrm{AK}\end{array}$ & - & $\begin{array}{c}<\mathrm{I} \times 10^{-7} \\
1.5 \\
<5 \times 10^{-9}\end{array}$ & oll & $\begin{array}{c}- \\
10 / 10\end{array}$ & - $3 / 109$ \\
\hline & $\begin{array}{l}\text { PMOXK(P-lac) } \\
\text { PMOXK(P-lac) }\end{array}$ & $\begin{array}{l}I \cdot 2 \\
3 \cdot 1\end{array}$ & $\underset{\mathrm{A}}{\mathrm{AK}}$ & - & $\begin{array}{c}<\mathrm{I} \times 10^{-8} \\
56 \$\end{array}$ & $\overline{0}$ & - & $\overline{0 / 8}$ \\
\hline 209 & $\begin{array}{l}\text { PM5006(P-lac) } \\
\text { PM5006(P-lac) } \\
\text { PM5006(P-lac) } \\
\text { PM5006(P-lac) }\end{array}$ & $\begin{array}{l}0.001 \\
0.001 \\
0.001 \\
3.1\end{array}$ & $\begin{array}{c}\text { K } \\
\text { A } \\
\text { AK } \\
\text { AK }\end{array}$ & $\begin{array}{l}- \\
3 \cdot 1 \\
-\end{array}$ & $\begin{array}{l}5 \times 10^{-2 * *} \\
1 \times 10^{-1 * *} \\
1 \times 10^{-1} \\
8 \times 10^{-2}\end{array}$ & $\begin{array}{c}\text { A, MorI74 } \\
\text { K, MorI74 } \\
\text { MorI74 } \\
\text { MorI74 }\end{array}$ & $\begin{array}{l}\text { ND } \\
\text { ND } \\
10 / 10 \\
10 / 10\end{array}$ & $\begin{array}{l}0 / 3 \\
0 / 5 \\
0 / 5 \\
0 / 3\end{array}$ \\
\hline & $\begin{array}{l}\text { PMOXK(P-lac) } \\
\text { PMOXK(P-lac) } \\
\text { PMOXK(P-lac) }\end{array}$ & $\begin{array}{l}3 \cdot 0 \\
3 \cdot 0 \\
3 \cdot 0\end{array}$ & $\begin{array}{c}\mathrm{K} \\
\mathrm{A} \\
\mathrm{AK}\end{array}$ & - & $\begin{array}{l}0 \ddagger \\
3 \ddagger \\
4 \ddagger\end{array}$ & $\begin{array}{c}\text { MorI74, K } \\
\text { MorI74 }\end{array}$ & $\begin{array}{l}\overline{3} / 3 \\
4 / 4\end{array}$ & $\begin{array}{l}- \\
0 / 3 \\
0 / 4\end{array}$ \\
\hline
\end{tabular}

ND, Not done.

* M.i., Multiplicity of input calculated on total particle concentration of lysate.

$\uparrow$ Transduction frequency per input phage particle.

$\S$ The denominator indicates the number of clones tested for ability to transfer transduced markers by conjugation to $E$. coli $\mathrm{J} 62-1$.

II Three clones in about 10000 tested by replica plating were Mor $174^{+}$.

The three transductants which could transfer were those which were Mori $74^{+}$.

** Minute transductants.

with titres I00-fold lower (Table 2, line 4). The plaque-forming titre of these two lysates had to be multiplied by a factor of $\mathrm{I} 0$ to yield their total particle content. Most of the plaques were small and hazy and the remainder resembled the wild type. The growth in all the small plaques replicated to kanamycin plus ampicillin agar while that in the large plaques failed to replicate to either agar. All the replica transductants were Mor $74^{+}$.

Transduction of markers by phage in induced lysates. The lysate derived from transductant no. I (Table 2, line I) (and nos 2, I00 and 200, not shown) transduced only the A marker to PM5006(P-lac) at frequencies greater than unity (Table 3, lines I to 3); it also yielded some transductants with PMOXK(P-lac) as recipient at a high multiplicity of input (Table 3, lines 4, 5). Three out of about 10000 transductants (including those from PMOXK), screened by the replica-plating method, were morganocinogenic and were named PM5006(P-lac $\overline{\mathrm{Mor}}$ 174A) (Table 3, line 2, column 7). These three were able to transfer the markers for $l a c^{+}$, morganocinogeny and ampicillin resistance to $\mathrm{J}_{62-\mathrm{I}}$ by conjugation (Table 3 , line 2, column 9). The transducing activity of phage in lysate no. 209 was dependent on the multiplicity of input. At very low multiplicities, only tiny transductant clones were observed after $48 \mathrm{~h}$ incubation, and transduction frequencies were high but variable (Table 3, lines 6, 7). At higher m.i. (Table 3, line 9) large transductant colonies had more or less completely replaced the tiny clones and transduction frequencies were high. A similar effect was produced by coinfection of cells with transducing phage at low m.o.i. and phage 5006M at high m.i. (Table 3, line 8). All transductants were MorI $74^{+}$and lysogenic. These transductants were named PM5006(P-lac $\overline{\text { MorI74KA }) . ~ P h a g e ~ i n ~ l y s a t e ~ n o . ~} 209$ was named 5006MHFTmorka. The same lysate also transduced the three markers to PMOXK $(\mathrm{P}-l a c)$ in small numbers at high 
J. N. COETZEE

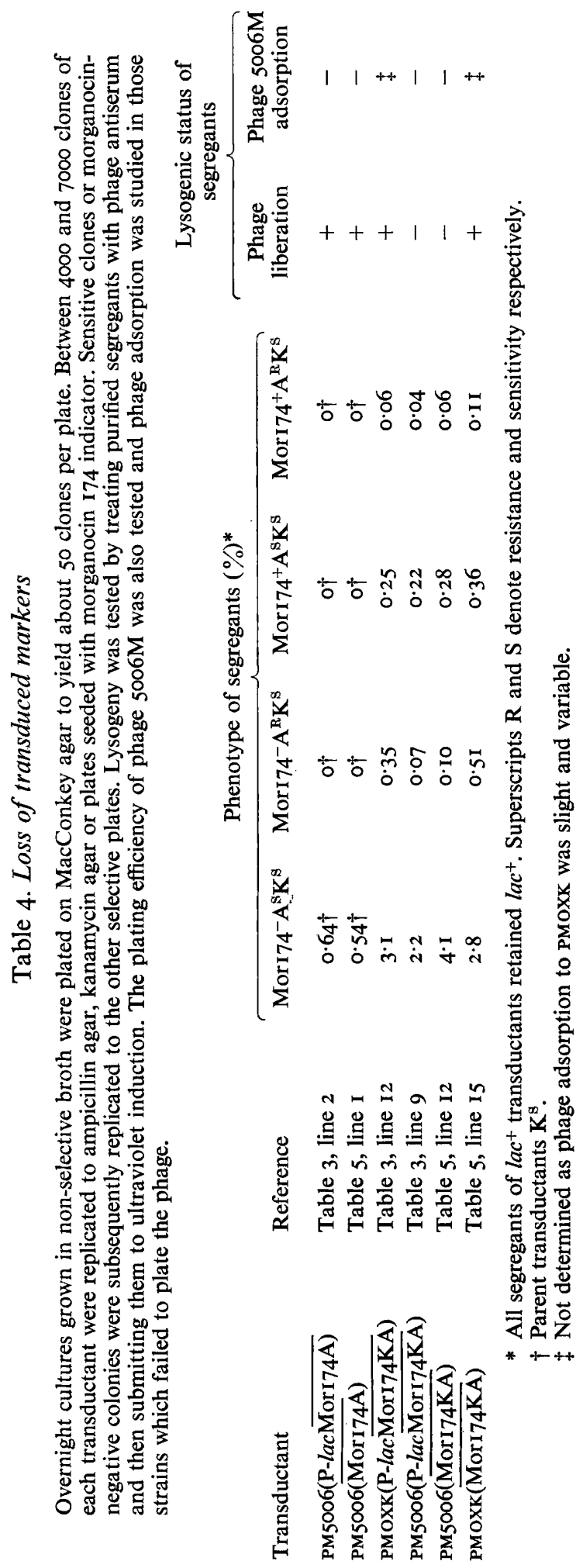


multiplicities of input (Table 3 , lines Io to I2). Transduction of antibiotic resistance markers by high frequency transducing variants of phage $5006 \mathrm{M}$ to Proteus strains, to which only slight and variable adsorption of phage, or none at all, could be demonstrated, has been described (Coetzee, 1975 b, 1976a, 1977). As adsorption of phage to PMOXK(P-lac) could not be measured the number of phage genomes involved was unknown. The latter transductants were labelled PMOXK(P-lac $\overline{\text { MorI } 74 \mathrm{KA}}$ ) and were lysogenic (Table 3, lines I I, I2). None of these transductants could transfer transduced markers to J62-I by conjugation. The lysate of transductant no. I58 (Table 2, line 4) gave similar results (not shown).

Segregation of markers of transductants PM5006(P-lac $\overline{\text { Mor I 74A }), ~ P M 5006(P-l a c ~} \overline{\text { Mor I 74KA) }}$ and PMOXK(P-lac Mor $74 \mathrm{KA})$. About $0.6 \%$ of colony-forming bacteria of transductant PM5006(P-lac $\overline{\text { MorI74A }) ~ l o s t ~ b o t h ~ t r a n s d u c e d ~ m a r k e r s ~ s i m u l t a n e o u s l y ~ a n d ~ s e g r e g a n t s ~ w e r e ~}$ still lysogenic (Table 4, line I). All three transduced markers segregated at higher frequencies from the other two transductants followed by loss of pairs of markers or a single marker at low frequencies (Table 4, lines 3,4). No matter which marker was selected, all segregants had lost the kanamycin resistance marker. The possible inactivation of a marker by integration of TnI in the corresponding gene (Coetzee, 1977) was not investigated. Segregants of PMOXK still liberated phage while those of PM5006 did not liberate phage but were still lysogenically converted to homologous phage non-adsorption (Table 4 , lines 3 , 4, columns $7,8)$.

Induction of transductants PM5006(P-lac $\overline{\text { MorI74A }), ~ P M 5006(P-l a c ~} \overline{\text { MorI 74KA) }}$ and

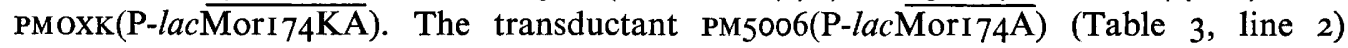
yielded a lysate with a titre of $3 \times 10^{9}$ plaque-forming units (p.f.u.) $\mathrm{ml}^{-1}$. These plaques resembled wild-type $5006 \mathrm{M}$ plaques and did not yield transductants when replicated to ampi-

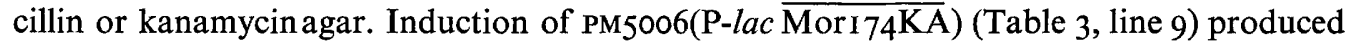
a lysate with a titre of $9 \times 10^{5}$ p.f.u. $\mathrm{ml}^{-1}$ on PM5006 and $80 \%$ of the plaques were small and hazy. The remainder resembled the wild-type plaque. This lysate contained many defective particles and the plaque-forming titre had to be multiplied by a factor of 14 to yield the total phage content. All small plaques replicated to ampicillin plus kanamycin agar and all

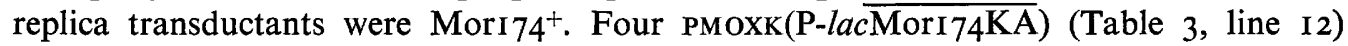
transductants (nos. 5 to 8) were induced. They produced lysates which plated on PM5006 to titres of $\mathrm{I} \times 10^{5}$ p.f.u. $\mathrm{ml}^{-1}$ but had no action on PMOXK. Lysates nos. 6 to 8 also produced about $80 \%$ small plaques while no. 5 mainly produced small plaques - only about $\mathrm{I} \%$ of plaques were large. The plaque-forming titre of lysates nos. 5 and 6 to 8 had to be multiplied by factors of 16 and 14 respectively to obtain an estimate the of total particle content. All small plaques replicated to kanamycin plus ampicillin agar and these replica transductants were all Mor $74^{+}$.

Transduction of markers by phage in induced lysates of PM5006(P-lac $\overline{\mathrm{MorI} 74 \mathrm{~A}})$,

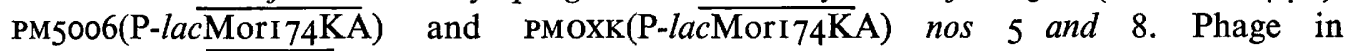
PM5006(P-lac $\overline{\mathrm{Mor} I 74 \mathrm{~A}}$ ) lysate cotransduced the A and MorI74 markers at low m.i. at frequencies of about $\mathrm{I} \times \mathrm{IO}^{-5}$ per p.f.u. adsorbed to PM5006. Co-infection with phage $5006 \mathrm{M}$ did not influence the transduction frequency (Table 5, lines $\mathrm{I}$ to 3 ). The markers were also transduced to PMOXK in low numbers (Table 5, line 4). None of the PM5006 or PMOXK transductants were capable of transferring markers to J62-I by conjugation (Table 5, lines I to 4, column 9) which probably meant that the same markers were previously transferred (Table 3, line 2, column 9) by the conjugative plasmid P-lac. The transducing phage present in the PM5006(P-lac $\overline{\text { Mor I74A }) ~ l y s a t e ~ w a s ~ n a m e d ~ p h a g e ~ 5006 M m o r a . ~ P h a g e ~ i n ~ l y s a t e ~}$ PM5006(P-lac $\overline{\text { MorI74KA }) ~ b e h a v e d ~ l i k e ~ p h a g e ~ 5006 M H F T m o r k a ~ i n ~ t h a t ~ i t ~ p r o d u c e d ~ o n l y ~}$ minute transductant clones at low m.i., but in the presence of helper phage or at higher input ratios transductant clones were of normal size and also arose at high frequency (Table 5, line 5 to 7). All markers were present and transductants were lysogenic, showed conversion to phage $5006 \mathrm{M}$ non-adsorption and could not transfer markers by conjugation to J62-I. Lysate PMOXK(P-lac $\overline{\text { MorI } 74 \mathrm{KA}})$ no. 8 had exactly the same properties as described 


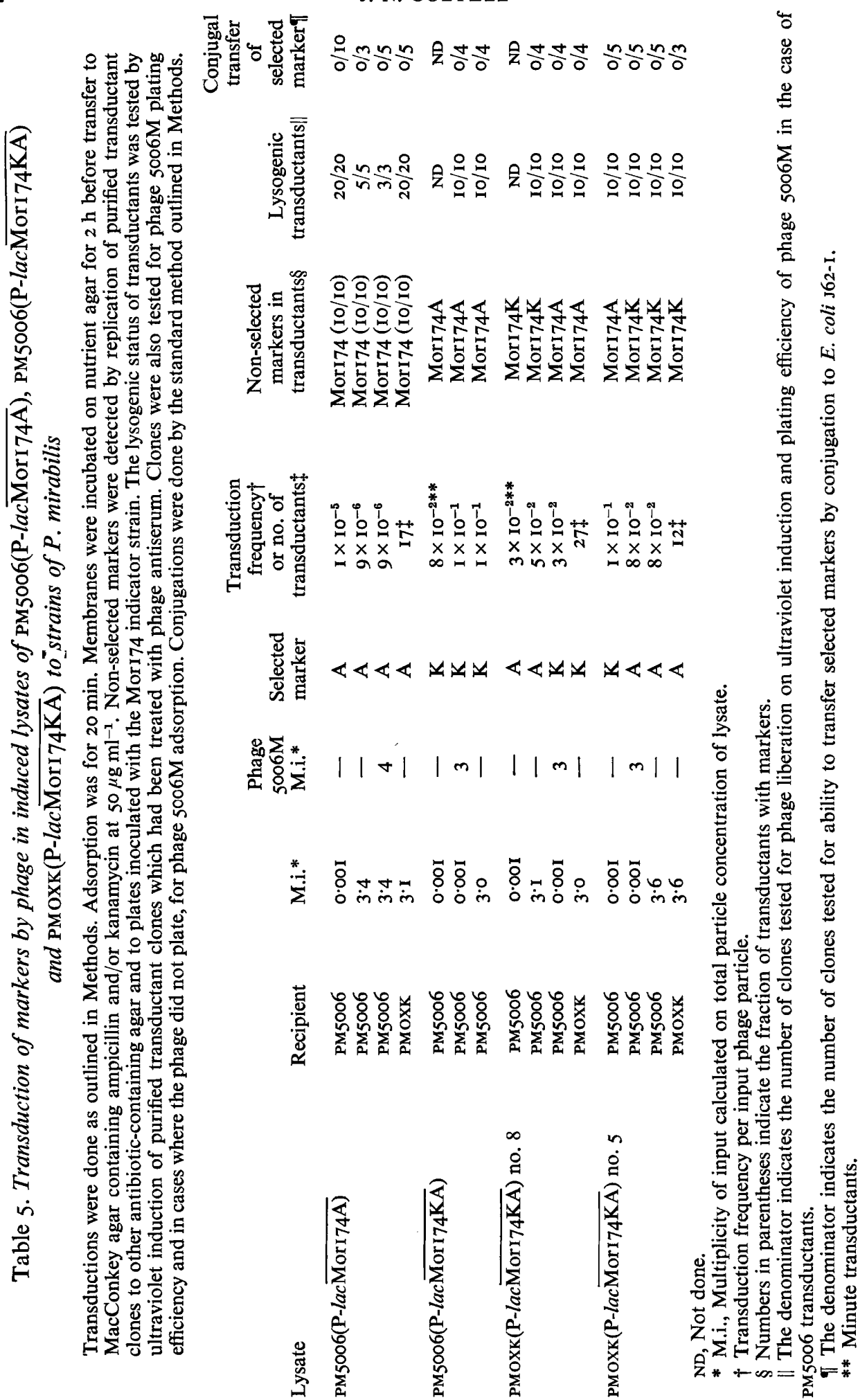




\title{
Table 6. Transduction of markers to PM5006 by phage in lysates of induced PM5006 transductants
}

\begin{abstract}
Phage lysates were obtained by ultraviolet induction of corresponding transductants. Transductions were done as outlined in Methods. Adsorption was for $20 \mathrm{~min}$. Membranes were incubated on nutrient agar for $2 \mathrm{~h}$ before transfer to MacConkey agar containing ampicillin or kanamycin at $50 \mu \mathrm{g} \mathrm{ml}^{-1}$. Non-selected markers were detected by replication of purified transductant clones to other antibiotic-containing agar and to plates inoculated with the MorI 74 indicator strain.
\end{abstract}

\begin{tabular}{|c|c|c|c|c|c|}
\hline Lysate & $\begin{array}{c}\text { Table } 5 \\
\text { reference }\end{array}$ & M.i.* & $\begin{array}{c}\text { Selected } \\
\text { marker }\end{array}$ & $\begin{array}{l}\text { Transduction } \\
\text { frequency }\end{array}$ & $\begin{array}{c}\text { Non-selected } \\
\text { markers }\end{array}$ \\
\hline PM5006( $\overline{\text { Mor174A }})$ & line $I$ & 0.005 & A & $8 \times 10^{-6}$ & $\operatorname{MorI} 74$ (10/10) \\
\hline PM5006(MorI74KA $)$ no. 3 & line 7 & 0.001 & A & I 7 & 0 \\
\hline PM5006(MorI74KA $)$ no. 2 & line 7 & 3 & $\mathbf{K}$ & $I \times 10^{-1}$ & Mori74, A (Io/Io) \\
\hline PM5006( $\overline{\text { MorI74KA }})$ no. 100 & line 9 & $2 \cdot 5$ & $\mathbf{A}$ & $\mathbf{I} \cdot 2$ & 0 \\
\hline PM5006( $\overline{\text { Mori74KA }) ~ n o . ~} 105$ & line 9 & $2 \cdot 2$ & $\mathrm{~K}$ & $<5 \times 10^{-8}$ & - \\
\hline PM5006(Mori74KA) no. 105 & line 9 & $2 \cdot 2$ & A & $<5 \times 10^{-9}$ & - \\
\hline PM5006(Mori74KA $)$ no. 500 & line 14 & $\mathbf{I} \cdot \mathbf{I}$ & A & $2 \cdot I$ & 0 \\
\hline PM5006(Mori74KA $)$ no. 509 & line 14 & $2 \cdot 1$ & A & $<5 \times 10^{-9}$ & - \\
\hline PM5006(Mori 74KA $)$ no. 509 & line 14 & $2 \cdot I$ & $\mathbf{K}$ & $\mathrm{I} \times 1 \mathrm{IO}^{-6}$ & Mori74 (10/10) \\
\hline
\end{tabular}

above (Table 5 , lines 8 to I I), but lysate no. 5 produced complete transductants even at low m.i. and transduction frequencies were not affected by helper phage (Table 5, lines I 2 to I5). Phage present in lysate no. 5 was named 5006 Mdpmorka, indicating defective plaque-forming transducing phage for the markers concerned.

\section{Properties of transductants}

Minute transductants. These were thought to be abortive transductants (Stocker, I956) because similar colonies did not develop when uninfected cells were plated on selective media. This is consistent with the observation that co-infection with phage $5006 \mathrm{M}$ (Table 3 , line 8 ; Table 5 , lines 6,10 ) decreased the number of minute transductants by converting them to complete large transductants. The minute transductants were not further investigated.

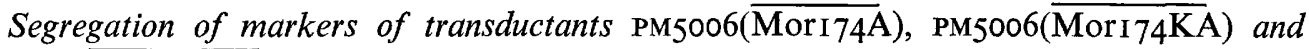
PMOXK( $\overline{\text { Mor I } 74 \mathrm{KA}})$. The pattern and frequencies of marker segregants was similar to that previously found, with simultaneous loss of markers from PM5006(MorI74A) (Table 4 , line 2) being less frequent than loss of markers from the other two transductants (Table 4, lines 5,6 ). The lysogenic status of the segregants was also the same as previously found (Table 4, lines I, 3, 4 and 2, 5, 6, columns 7,8).

Ultraviolet light induction. Transductants PM5006( $\overline{\text { MorI } 74 \mathrm{~A}}$ ) were lysogenic (Table 5, lines $\mathrm{I}$ to 3 ) and yielded phage lysates with titres of $\mathrm{I} \times 10^{9}$ to $4 \times 10^{9}$ p.f.u. $\mathrm{ml}^{-1}$, similar to those produced by PM5006(P-lac $\overline{\text { MorI74A }) ~(s e e ~ a b o v e) . ~ P h a g e ~ i n ~ t h e s e ~ l y s a t e s ~ c o t r a n s d u c e d ~}$ the markers at similar frequencies (Table 6, line $\mathrm{I}$ ) to those listed in Table 5, lines $\mathrm{I}$ to 3 . Induction of three PM5006 transductants (nos. I to 3) by lysate PM5006(P-lac $\overline{\text { MorI74KA })-~}$ phage 5006MHFTmorka-(Table 5, line 7) yielded lysates with plaque-forming titres of about $\mathrm{I} \times 10^{6} \mathrm{ml}^{-1}$ with the same distribution of plaque-types as phage 5006MHFTmorka lysates. However, growth in the small plaques produced by phage in lysates nos I and 3 replicated only to ampicillin agar and the replica growth was not morganocinogenic (also see Table 6, line 2). Phage in lysate no. 2 (Table 6, line 3) had properties similar to phage 5006MHFTmorka. Induction of seven PM5006 transductants produced by lysate PMOXK 
(P-lac $\overline{\text { MorI 74KA }}$ ) no. 8 (Table 5, line 9) produced lysates with different transducing potentials. Two of the lysates (nos 100 and 102) plated on PM5006 yielding mostly small hazy plaques. Growth in these plaques only replicated to ampicillin agar and replica transductants were not morganocinogenic (see Table 6, line 4). Another lysate (no. 105) yielded only large plaques which did not transduce resistance to kanamycin or ampicillin (morganocinogeny was not selected for) (Table 6, lines 5, 6). Four other lysates (nos. I09, II2, II4 and I20) contained particles with properties similar to phage 5006MHFTmorka (not shown). Induction of the 27 PMOXK transductants produced by phage in the lysate PMOXK (Plac- $\overline{\text { MorI } 74 \mathrm{KA}}$ ) no. 8 (Table 5, line I I) produced lysates with properties similar to the latter lysate, i.e. phage 5006MHFTmorka (not shown). Induction of 10 PM5006 transductants by

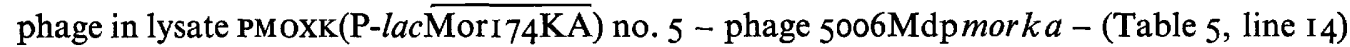
again yielded an array of transducing lysates. One (no. 500) only transduced ampicillin resistance to PM5006 (Table 6, line 7). Another (no. 509) transduced kanamycin resistance and morganocinogeny (but not ampicillin resistance) to PM5006 at frequencies of $\mathrm{I} \times \mathrm{IO}^{-6}$ per input phage (Table 6 , lines 8,9 ). Both the latter lysates only formed large plaques on PM5006 and, in common with all lysates, had no visible action on PMOXK. The remaining eight transductants yielded lysates containing phage with properties identical to that in lysate PMOXK(P-lac $\overline{\mathrm{MorI}} 74 \mathrm{KA})$ no. 5, i.e. phage 5006Mdpmorka (not shown). Again, phage in all I2 lysates of PMOXK transductants by PMOXK(P-lac $\overline{\text { MorI74KA }) ~ n o . ~} 5$ lysate phage $5006 \mathrm{Mdpmorka-(Table} \mathrm{5,} \mathrm{line} 15$ ) behaved in the same way as the producing lysate (not shown).

\section{Properties of phages}

Neutralization by antiserum. The plaque-forming titres of phages 5006M, 5006 Mmora, $5006 \mathrm{MHFT}$ mork $a$ and $5006 \mathrm{Mdp}$ mork $a$ were neutralized at frequencies of $170 \mathrm{~min}^{-1}$ and were considered to be serologically identical.

Concentration dependence of plaque assay. The formation of small plaques by phage 5006MHFTmorka was multiplicity dependent and the lysate plated as a function of the square of concentration (Fig. I). Large plaques produced by this lysate, as well as plaques by phages $5006 \mathrm{Mdpmorka}$ and 5006Mmora, showed a linear relationship to dilution plated (Fig. I).

Transduction frequencies and multiplicities of phage infection. The frequency of phage $5006 \mathrm{Mdp}$ mork $a$ transduction of the ampicillin and kanamycin markers to PM5006 remained constant over a large range of multiplicities of input (Fig. 2). Transductions by phage 5006MHFTmorka, on the other hand, were multiplicity dependent. At multiplicities of phage input below one particle per cell, the number of ampicillin and kanamycin resistant transductants (which were all Mor $74^{+}$) decreased as the square of the particle concentration (Fig. 2). However, in the presence of multiple infection by non-defective helper phage, the transduction frequency of phage 5006MHFTmorka was restored to previous levels irrespective of the multiplicity of input (Fig. 2).

Ultraviolet irradiation of phage lysates. Attempts were made to determine the position of transduced markers relative to the chromosome of the recipient by studying the effect which ultraviolet irradiation of transducing lysates had on transduction frequencies of markers (Arber, 1960; Luria, Adams \& Ting, 1960). The progressive decrease in transduction frequencies of markers of all phages with increasing exposure (Fig. 3), favoured either an extrachromosomal location of markers or the possibility that markers were part of a phage genome which had integrated in the host chromosome by a single crossover event (Campbell, I962). 


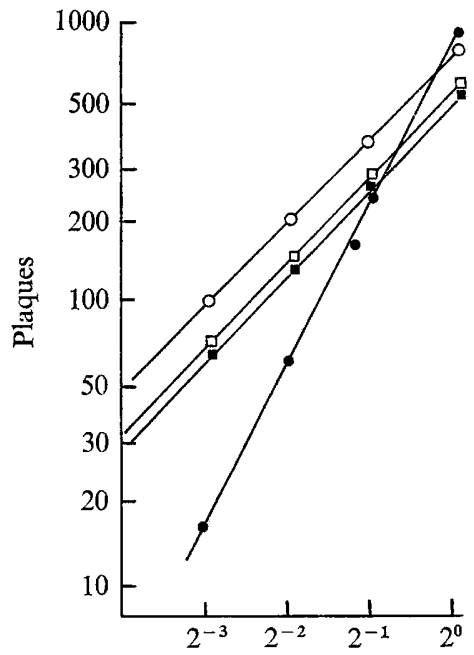

Relative concn of lysate

Fig. I

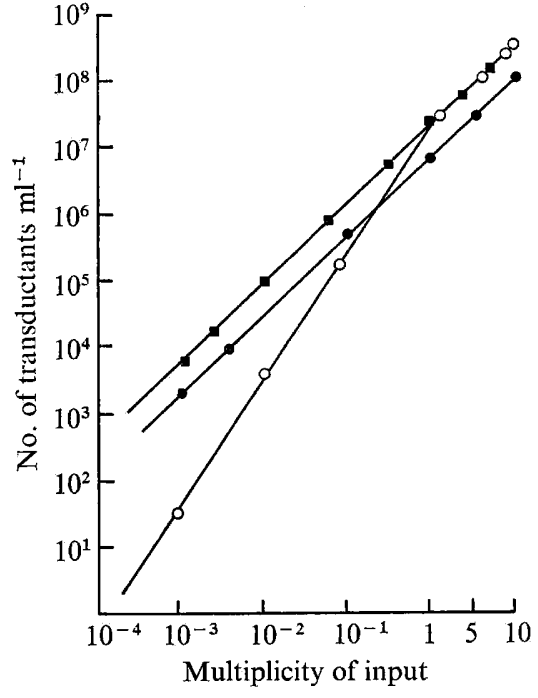

Fig. 2

Fig. x. Concentration dependence of plaque assay. Serial doubling dilutions of purified phage lysates were titrated with constant volumes of a buffered saline suspension of PM5006. To obtain statistically significant numbers of the large plaque-forming particles in the phage 5006MHFTmorka lysate, more than one plate per dilution was prepared. $\square$, Phage 5006Mmora; 9 , phage 5006MHFTmorka small plaques; $\square$, phage 5006MHFTmorka large plaques; $\bigcirc$, phage $5006 \mathrm{Mdpmorka.}$

Fig. 2. Effect of multiplicity of input of phage on the transduction of ampicillin and kanamycin resistances. Transductions were done as outlined in Methods and suitable dilutions of the adsorption mixture were filtered to determine the number of transductants. The results show the total numbers of ampicillin and kanamycin resistant transductants per $\mathrm{ml}$ of adsorption mixture. The total particle titre of phage 5006MHFTmor $k a$ was 44 times, and that of phage 5006Mdpmor $k a$ was 16 times the plaque-forming titre on PM5006. O, Phage 5006MHFT morka alone; $\mathbf{m}$, phage 5006MHFTmorka plus phage 5006M at m.i. 4; 9 , phage 5006Mdpmorka.

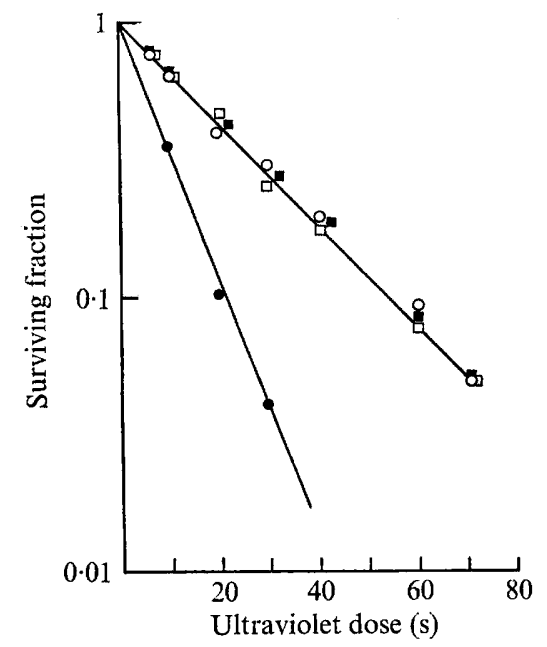

Fig. 3. Effect of ultraviolet irradiation on phage lysates. Quantitative transduction experiments were done with phage in the irradiated lysates at m.i. of unirradiated phage of 3. Selection was for ampicillin resistance with phage 5006Mmora and for ampicillin and kanamycin resistance with phages 5006Mmorka and 5006Mdpmorka. $\square$, Transducing activity of phage 5006Mmora; $\mathbf{\square}$, transducing activity of phage 5006Mmorka; $\mathrm{O}$, transducing activity of phage 5006 Mdpmorka; , plaque formation by all lysates on PM5006. 


\section{DISCUSSION}

With the vast majority of phage 5006Mpa transductants it is suggested that the phage had merely lysogenized recipients leaving the MorI $74 \mathrm{R} 772$ complex untouched and still susceptible to transfer by the resident P-lac plasmid (Table 2, lines I to 3). On induction of transductant no. I, the ampicillin marker of the vegetative phage in one or a small number of cells transposed to the MorI $74 \mathrm{R} 772$ plasmid with inactivation of the kanamycin resistance marker of the latter. This new plasmid was then taken up in a phage capsid and this could account for the three morganocinogenic ampicillin-resistant transductants produced by this lysate (Table 3 , line 2 , column 7 ) with recipient PM5006(P-lac). The fact that the markers could be transferred by conjugation (Table 3, line 2, column 9) meant that the plasmid was deposited intact and extrachromosomally by the phage. Induction of these transductants would result in further chance-envelopment by capsids with subsequent transfer to new recipients. Results of segregation studies on these transductants (Table 4, lines $I, 2)$ are compatible with loss of a single-copy plasmid (see below) bearing both markers. The relatively high transduction frequency could result from the extrachromosomal nature of events and be a measure of the adsorption frequency of the particles involved (see Arber, 1960; Iordănescu, 1975; Shipley \& Olsen, 1975). This course of events was supported by the steady decrease in transduction frequencies with increasing irradiation of the transducing lysate (Fig. 3), the fact that the frequencies were not affected by helper phage (Table 5, line 3, column 4) and that the particles in transducing lysates plated linearly (Fig. I). The fact that at low m.i. transductants were lysogenic (Table 5, line I) could mean that transducing particles contained some phage genes (Schmieger, 1970) which, on integration in tandem to the cryptic prophage, rendered the latter inducible (Krizsanovich, 1973; Coetzee, $1974 b$ ). The addition of TnI to the Mor 74 R 772 complex (already shortened for accommodation in the phage 5006M capsid - see Coetzee et al., 1977) could be in the kanamycin resistance gene (thus accounting for inactivation of the latter) (Heffron, Rubens \& Falkow, I975; Hedges \& Jacob, I974; Berg et al., 1975; Kleckner et al., 1975; and see Freeman, Bibb \& Hopwood, 1977) or to another portion of the plasmid accompanied by a deletion in the latter gene (see Lee et al., 1974; Kleckner et al., 1975; Reif \& Saedler, 1975, 1976). The last explanation is favoured as it need not involve an increase in mass. The fact that markers of the plasmid were non-transferable by conjugation in the absence of P-lac (Table 5, lines I to 4 , column 9) could imply that, just like the parent (Coetzee et al., I977), this recombinant required a conjugative plasmid for transfer.

A different course of events must have followed entry of phage $5006 \mathrm{Mp} a$ genomes into PM5006(P-lac $\overline{\text { MorI } 74 \mathrm{~K}}$ ) to form transductants nos 158 and 209 as only P-lac was transferable to J62-I by conjugation (Table 2 , lines 4 to 6 ). This could mean that the Mor $174 \mathrm{R} 772$ complex had integrated in the chromosome, or possibly that a gene on this plasmid, necessary for its mobilization by P-lac, had been inactivated by addition of TnI. The latter phenotype would correspond to a Mob-ColEI (Warren \& Sherratt, I977; Hershfield et al., I976). Mori 74 is a multicopy plasmid maintaining 30 to 40 copies per genome equivalent in P. morganii I 74 (Williams, I977), like low molecular weight colicinogenic factors (Hardy, I975). It is not known how many copies of it or the Mor ${ }_{74} \mathbf{R} 722$ complex are present in host PM5006. Recombinant plasmids have been described (Hershfield et al., 1976) which have different copy numbers from parent replicons. It is also undetermined whether an incompatibility situation exists between integrated and extrachromosomal states of the complex as encountered with the F factor (Scaife \& Gross, 1962; Maas, I963). In any case, for the phenotype to have been detected, unaffected copies of plasmid Mor I $74 \mathrm{R} 772$ (if they existed) must have been removed.

The thesis put forward here is that markers of the Mor $174 \mathrm{R} 772$ plasmid inserted contiguously to the ampicillin resistance gene in the prophage $5006 \mathrm{Mp} a$-cryptic prophage $5006 \mathrm{M}$ sequence on the PM5006 chromosome. Whether this was facilitated or even mediated 
by TnI (Cohen, I976; Robinson, Bennett \& Richmond, 1977) is not known. However with excision of the oversized prophage(s) on induction, the insertion caused derangement of the encapsidated genomes. Instead of being terminally redundant with each particle carrying a complete (permuted) set of genes like the wild type, these genomes lacked terminal repetition and some (not always the same) genes. Such populations of phage, while possessing all genetic information as a group, were individually defective and depended on mutual aid for propagation. The insertion model has been meticulously elucidated (Chan et al., 1972; Tye, Chan \& Botstein, 1974; Chan \& Botstein, 1976) for the circularly permuted, terminally redundant phage $P_{22}$ and the size of inserted DNA could approach that of the phage headful (Tye et al., 1974). Two linear defective genomes would recombine to form a terminally repetitious doublet which could then circularize and integrate by a single crossover in the chromosome. This mutual aid is reflected both in the multiplicity dependence of phage 5006MHFTmork $a$ plaque formation (Fig. I) and the multiplicity of infection necessary for complete transduction of markers (Fig. 2).

The abortive transductants encountered with single infection by phage 5006MHFTmork $a$ did not influence the steady decline in transduction frequencies with increasing dose of ultraviolet irradiation to the phage lysate (Fig. 3). When good homology exists between markers and chromosome, small doses of irradiation often stimulate double crossover events and result in an initial increase in transduction frequencies (Luria et al., I960; Lacey, I973; Drexler \& Kylberg, I975; Tagg et al., 1976; Pemberton \& Tucker, I977). Here it is assumed that no such homology existed (Jessop, 1976) and the only way of getting transduced markers attached to the chromosome was by doublet formation. The properties of phage $5006 \mathrm{Mdp}$ mork $a$ are compatible with an origin as a deletion of some genetic material of prophage 5006MHFTmork $a$ in PMOXK. Deletion has been described in association with transpositions and insertions (see Kopecko \& Cohen, 1975; Kleckner et al., 1975; Ahmed \& Johansen, I 975; Reif \& Saedler, 1976) and as a result of ultraviolet irradiation of lysogens (Chan et al., 1972). On being excised this phage genome would now have its terminal redundancy restored and could function independently provided the material lost was expendable. That this was so is shown by the linear relationships existing between plaque formation (Fig. I), transduction frequency (Fig. 2) and multiplicity of infection. Obviously these phages were defective in some function(s) associated with plaque formation, possibly in the ease with which infecting genomes were reduced to prophage. On the other hand, loss of the inserted piece would completely restore the genome and this is given as an explanation for the presence of a variable proportion of wild-type phage in the lysates. The fact that transduced markers were usually lost en bloc at an appreciable frequency (Table 4 , lines 3 to 6 ) and that transductants were lysogenic usually yielding transducing phage, suggested that the entire transducing phage had been integrated in the bacterial chromosome and that transductants were heterogenote-like (Luria et al., 1960; Jessop, 1972).

The fragmentation or rearrangement of incoming genomes of phages 5006MHFTmorka and 5006Mdpmorka often encountered in PM5006 (see above and Table 6, lines 2 to 9) was a unique event not associated with any of the other Proteus high frequency transducing systems (Coetzee, 1974 $b$, 1975a, 1796b, 1977). This phenomenon was mostly (but not exclusively) encountered with PM5006 transductants by phage assembled in PMOXK. In PMOXK the phages bred true and PMOXK transductants form the only reliable source of these phages at present. Strain PM5006 possesses a host modification system (Coetzee \& Smit, 1970). This system has not yet been studied in relation to PMOXK, one encumbrance being that none of the phages investigated plates on the latter organism. Transduction frequencies were high, however, and extensive degradation of incoming DNA by PM5006 was unlikely (Coetzee \& Smit, 1969). A further indication of possible derangement of prophage genes in PM5006 was the altered lysogenic status of segregants from lysogenic transductants of only the latter strain. These segregants for one or more markers failed to liberate phage on induction but retained the property of lysogenic conversion to homologous phage non-adsorption 
(Table 4, lines 4, 5). Although the mechanism is not understood, there is possibly a nice distinction between genes involved in induction of prophage and those responsible for lysogenic conversion to homologous phage non-adsorption (see Coetzee, $1961,1974 b$; Krizsanovich, 1973). It is unlikely that translocation of TnI played a role as it was also present in transductants of PMOXK. Apart from not knowing the number of phage genomes involved in PMOXK transductant formation (see above), another factor which could have contributed to differences between the PMOXK and PM5006 transductants was the presence of the cryptic prophage in PM5006 (Krizsanovich, 1973). The cryptic prophage remains an enigma. It could apparently not substitute for a wild-type (or another defective) genome in the transduction by lysogenization (Luria et al., I960) described here for phage 5006MHFTmorka. This form of cooperation is well known between prophage and infecting genomes in the P22 system (Chan \& Botstein, 1976; Jessop, 1976; see also Rosner, 1975). However the cryptic prophage may have played a part in the rearrangement of markers of incoming transducing particles mentioned above. No form of lysogeny has been demonstrated in PMOXK (unpublished; Vieu \& Capponi, 1965) and the sensitivity of this strain to many Proteus phages (Brandis \& Schwarzrock, I965; Vieu \& Ducrest, 196I) would support the contention that it carries no prophage.

In view of the serological relationship between PMOXK and Rickettsia tsutsugamushi (Wilson \& Miles, 1975), it may now be possible to attempt the introduction of markers carried by various Proteus high frequency transducing phages into this organism.

The author is in receipt of grants from the South African Medical Research Council.

\section{REFERENCES}

ADAMs, M. H. (1956). Methods of study of bacterial viruses. Methods in Medical Research 2, I-73.

AHMeD, A. \& Johansen, E. (1975). Reversion of the gals mutation of Escherichia coli: partial deletion of the insertion sequence. Molecular and General Genetics 142, 263-275.

ARBER, W. (1960). Transduction of chromosomal genes and episomes in Escherichia coli. Virology II, 273-288.

Berg, D. E., Davies, J., Allet, B. \& Rochaix, J. D. (1975). Transposition of $R$ factor genes to bacteriophage $\lambda$. Proceedings of the National Academy of Sciences of the United States of America 72, 3628-3632.

Botstein, D. (1968). Synthesis and maturation of phage P22 DNA. I. Identification of intermediates. Journal of Molecular Biology 34, 62 I-64I.

Bramucci, M. G. \& LovetT, P. S. (1976). Lowfrequency, PBSI-mediated plasmid transduction in Bacillus pumilus. Journal of Bacteriology 127, 829-83I.

Brandis, H. \& SchwarzRock, A. (1956). Über Proteus-Bakteriophagen. Zentralblatt für Bakteriologie, Parasitenkunde, Infektionskrankheiten und Hygiene (Abteilung I, Originale) 165, 226-232.

Cabezón, T., Faelen, M., De Wilde, M., Bollen, A. \& Thomas, R. (1975). Expression of ribosomal protein genes in Escherichia coli. Molecular and General Genetics 137, I25-I 29.

Campbell, A. (1962). Episomes. Advances in Genetics 12, 10I-145.

Chan, R. K. \& Botstein, D. (1976). Specialized transduction by bacteriophage $\mathbf{P}_{22}$ in Salmonella typhimurium: genetic and physical structure of the transducing genomes and the prophage attachment site. Genetics $83,433-458$.

Chan, R. K., Botstein, D., Watanabe, T. \& Ogata, Y. (I972). Specialized transduction of tetracycline resistance by phage $\mathbf{P}_{22}$ in Salmonella typhimurium. Virology 50, 883-898.

Clowes, R. C. \& HAYES, W. (1968). Experiments in Microbial Genetics, p. 227. Oxford and Edinburgh: Blackwell Scientific Publications.

Coetzee, J. N. (I96I). Lysogenic conversion in the genus Proteus. Nature, London 189, 946-947.

Coetzee, J. N. (1974a). Properties of Proteus and Providence strains harbouring recombinant plasmids between P-lac and RIdrdI9 or R447b. Journal of General Microbiology 80, I I9-130.

CoetzeE, J. N. (I974b). High frequency transduction of kanamycin resistance in Proteus mirabilis. Journal of General Microbiology 84, 285-296.

CoetzeE, J. N. (I975a). High frequency transduction of ampicillin and kanamycin resistance in Proteus mirabilis. Journal of General Microbiology 87, I73-176.

Coetzee, J. N. (I975 $b$ ). Transduction of a Proteus vulgaris strain by a $P$. mirabilis bacteriophage. Journal of General Microbiology 89, 299-309.

CoETZEe, J. N. (1976a). Intra-species transduction with Proteus mirabilis high frequency transducing phages. Journal of General Microbiology 93, 153I 65.

CoETzee, J. N. (1976b). Derivation and properties of Proteus mirabilis systems for high frequency transduction of streptomycin - sulphonamide and streptomycin-sulphonamide-kanamycin resistances. Journal of General Microbiology 96, 95-107. 
Coetzee, J. N. (1977). Derivation of a Proteus mirabilis converting phage for ampicillin resisrance. Journal of General Microbiology 99, I27138.

Coetzee, J. N. \& SACKs, T. G. (I960). Transduction of streptomycin resistance in Proteus mirabilis. Journal of General Microbiology 23, 445-455.

Coetzee, J. N. \& Smit, J. A. (1969). Restriction of a transducing bacteriophage in a strain of Proteus mirabilis. Journal of General Virology 4, 593-607.

Coetzee, J. N. \& SMIT, J. A. (1970). Properties of Proteus mirabilis phage 13vir. Journal of General Virology 9, 247-249.

Coetzee, J. N., Datta, N., Hedges, R. W. \& Appelbaum, P. C. (1973). Transduction of $\mathbf{R}$ factors in Proteus mirabilis and $P$. rettgeri. Journal of General Microbiology 76, 355-368.

Coetzee, J. N., Krizsanovich-Williams, K. \& Williams, J. A. (I977). Cotransduction of morganocinogenic plasmid $\mathrm{I} 74$ and $\mathbf{R}$ factor R772. Journal of General Microbiology 100, 299308.

CoHEN, S. N. (1976). Transposable genetic elements and plasmid evolution. Nature, London, 263, 73 I738.

Dempsey, W. B. \& Willetts, N. S. (1976). Plasmid co-integrates of prophage lambda and $\mathbf{R}$ factor I00. Journal of Bacteriology 126, I66-176.

DreXler, H. \& KYlberG, K. J. (1975). Effect of UV irradiation on transduction by coliphage $T I$. Journal of Virology r6, 263-266.

Falkow, W., Wohlhieter, J. A., Citarella, R. V. \& Baron, L. S. (1964). Transfer of episomic elements to Proteus. Journal of Bacteriology 88, I598-I60I.

FredericQ, P. \& Delhalle, E. (I972). Recombinaison entre facteurs $\mathrm{R}$ et facteurs colicinogènes chez Escherichia coli KI2. Annales de l'Institut Pasteur 122, 909-92 I.

Freeman, R. F., Bibb, M. J. \& Hopwood, D. A. (1977). Chloramphenicol acetyltransferaseindependent chloramphenicol resistance in Streptomyces coelicolor A3(2). Journal of General Microbiology 98, 453-465.

Fukumaki, Y., Shimada, K. \& TAKagi, Y. (I976). Specialized transduction of colicin EI DNA in Escherichia coli $\mathrm{K}-\mathrm{I} 2$ by phage lambda. Proceedings of the National Academy of Sciences of the United States of America 73, 3238-3242.

Grabow, W. O. K. (1972). Growth-inhibiting metabolities of Proteus mirabilis. Journal of Medical Microbiology 5, 191-196.

Grabow, W. O. K. \& SmIT, J. A. (1967). Methionine synthesis in Proteus mirabilis. Journal of General Microbiology 46, 47-57.

HARDY, K. G. (1975). Colicinogeny and related phenomena. Bacteriological Reviews 39, 464-515.

Hedges, R. W. (1975). R factors from Proteus mirabilis and $P$. vulgaris. Journal of General Microbiology 87, 30 I-3 Ir.

Hedges, R. W. \& JACOB, A. E. (1974). Transposition of ampicillin resistance from $\mathrm{RP}_{4}$ to other replicons. Molecular and General Genetics 132, 3I-40.

Heffron, F., Rubens, C. \& Falkow, S. (1975). Translocation of a plasmid DNA sequence which mediates ampicillin resistance: molecular nature and specificity of insertion. Proceedings of the National Academy of Sciences of the United States of America 72, 3623-3672.

HeRshField, V., Boyer, H.W., ChOW, L. \& Helinski, D. R. (1976). Characterization of a mini-ColEI plasmid. Journal of Bacteriology 126, 447-453.

IORDǍNESCU, S. (1975). Recombinant plasmid obtained from two different compatible staphylococcal plasmids. Journal of Bacteriology 124, 597-60I.

JessoP, A. P. (1972). A specialized transducing phage of $P_{22}$ for which the ability to form plaques is associated with transduction of the proAB region. Molecular and General Genetics 114, 214222.

Jessop, A. P. (1976). Specialized transducing phages derived from phage $\mathrm{P}_{22}$ that carry the proAB region of the host, Salmonella typhimurium: genetic evidence for their structure and mode of transduction. Genetics 83, 459-475.

KLECKNER, N., ChAN, R. K., TYE, B. K. \& BotsteIN, D. (1975). Mutagenesis by insertion of a drugresistance element carrying an inverted repetition. Journal of Molecular Biology 97, 56I-575.

Kopecko, D. J. \& CoHEN, S. N. (1975). Site specific rec $A$-independent recombination between bacterial plasmids: involvement of palindromes at the recombinational loci. Proceedings of the National Academy of Sciences of the United States of America 72, 1373-1377.

Krizsanovich, K. (I973). Cryptic lysogeny in Proteus mirabilis. Journal of General Virology 19, 3I I-320.

LACEY, R. W. (1973). Genetic basis, epidemiology, and future significance of antibiotic resistance in Staphylococcus aureus: a review. Journal of Clinical Pathology 26, 899-9r3.

Lee, H. J., Ohtsubo, E., Deonier, R. C. \& Davidson, N. (I974). Electron microscope heteroduplex studies of sequence relations among plasmids of Escherichia coli. V. ilv $v^{+}$deletion mutants of FI4. Journal of Molecular Biology 89, 585-597.

LovetT, P. S., Duvall, E. J. \& KegGings, K. M. (1976). Bacillus pumilus plasmid pPLio: properties and insertion into Bacillus subtilis $\mathrm{I} 68$ by transformation. Journal of Bacteriology 127, $817-828$.

Luria, S. E., Adams, J. N. \& Ting, R. C. (I960). Transduction of lactose-utilizing ability among strains of $E$. coli and $S$. dysenteriae and the properties of the transducing phage particles. Virology 12, 348-390.

MAAS, R. (1963). Exclusion of an F-lac episome by an HFR gene. Proceedings of the National Academy of Sciences of the United States of America 50, I05I-1055.

Manly, K. F., Signer, E. R. \& Radding, C. M. (1969). Nonessential functions of bacteriophage $\lambda$. Virology 37, I77-188.

Pemberton, J. M. \& Tucker, W. T. (1977). Naturally occurring viral $R$ plasmid with a circular supercoiled genome in the extracellular state. Nature, London 266, 50-5I.

ReIF, H. J. \& SAEDLER, H. (I975). ISI is involved in deletion formation in the $\mathrm{gal}$ region of $E$. coli K12. Molecular and General Genetics 137, 17-28. 
REIF, H. J. \& SAEDLER, H. (1976). ISI-dependent deletion formation in the $\mathrm{gal}$ region of the $E$. coli chromosome. Genetics 83, S6I-S62.

RoBinson, M. K., BENNETT, P. M. \& Richmond, M. H. (1977). Inhibition of TnA translocation by TnA. Journal of Bacteriology 129, 407-4I4.

ROSNER, J. L. (1975). Specialized transduction of pro genes by coliphage PI. Structure of a partly diploid PI-pro prophage. Virology 66, 42-55.

SCAIFE, J. \& Gross, J.D. (I962). Inhibition of multiplication of an F-lac factor in HFR cells of Escherichia coli K-12. Biochemical and Biophysical Research Communications 7, 403-407.

SCHMIEGER, H. (1970). The molecular structure of the transducing particles of Salmonella phage P22. II. Density gradient analysis of DNA. Molecular and General Genetics 109, 323-337.

SHIPLEY, P. L. \& OlSEN, R. H. (1975). Isolation of a nontransmissible antibiotic resistance plasmid by transductional shortening of $\mathrm{R}$ factor RPI. Journal of Bacteriology 123, 20-27.

Starlinger, P. \& SAedler, H. (1972). Insertion mutations in micro-organisms. Biochimie 54, 177185.

Starlinger, P. \& SAEDleR, H. (1976). IS-elements in micro-organisms. Current Topics in Microbiology and Immunology 75, I I I-I 52.

StOCKER, B. A. D. (1956). Abortive transduction of motility in Salmonella: a non-replicated gene transmitted through many generations to a single descendant. Journal of General Microbiology 15, 575-598.

TAGG, J. R., SkJold, S. \& Wannamaker, L.W.
(1976). Transduction of bacteriocin determinants in Group A streptococci. Journal of Experimental Medicine 143, I 540-1544.

Threlfall, E. J. \& Holland, I. B. (I970). Cotransduction with $\operatorname{ser} \mathrm{B}$ of a pleiotropic mutation affecting colicin E2 refractivity, ultraviolet sensitivity, recombination proficiency and surface properties of Escherichia coli K12. Journal of General Microbiology 62, 383-398.

Tye, B. K., Chan, R. K. \& Botstein, D. (1974). Packaging of an oversize transducing genome by Salmonella phage P22. Journal of Molecular Biology 85, 485-500.

VIEU, J. F. \& CAPPONI, M. (1965). Lysotypie des Proteus oxI9, oxK, Ox2 et oxL. Annales de l'Institut Pasteur 108, 103-106.

VIEU, J. F. \& DUCREST, P. (I96I). Notions nouvelles sur la lysotypie de Proteus hauseri: le lysotype I. Zentralblatt für Bakteriologie, Parasitenkunde, Infektionskrankheiten und Hygiene (Abteilung I, Originale) 182, 49-56.

WARREN, G. \& SHERRATT, D. (1977). Complementation of transfer deficient ColEr mutants. Molecular and General Genetics 15I, 197-20I.

WILLIAMS, J. A. (1977). Mobilization of morganocin 174 plasmid and kinetics of morganocin production in Proteus and Escherichia coli hosts. Antimicrobial Agents and Chemotherapy Ir, 514520.

Wilson, G. S. \& Miles, A. (1975). Topley and Wilson's Principles of Bacteriology, Virology and Immunity, 6th edn, pp. 235I-2352. London: Edward Arnold. 